\title{
Affordances in Interaction: The Case of Aikido
}

\section{Michael Kimmel \& Christian R. Rogler}

To cite this article: Michael Kimmel \& Christian R. Rogler (2018) Affordances in Interaction: The Case of Aikido, Ecological Psychology, 30:3, 195-223, DOI: 10.1080/10407413.2017.1409589

To link to this article: https://doi.org/10.1080/10407413.2017.1409589

(C) The Author(s). Published with license
by Taylor \& Francis Group, LLC@ Michael
Kimmel and Christian R. Rogler




\title{
Ә OPEN ACCESS
}

\section{Affordances in Interaction: The Case of Aikido}

\author{
Michael Kimmel ${ }^{\mathrm{a}}$ and Christian R. Rogler ${ }^{\mathrm{b}}$ \\ ${ }^{\mathrm{a} C o g n i t i v e ~ S c i e n c e ~ P l a t f o r m, ~ U n i v e r s i t y ~ o f ~ V i e n n a ; ~}{ }^{\mathrm{b}}$ Department of Social and Cultural Anthropology, University \\ of Vienna
}

\begin{abstract}
Our title can be read as trivially true, namely, that perceived affordances shape real-time interaction dynamics. A less trivial reading suggests that affordances themselves interact in a shared dyadic field, such that the number and quality of As and Bs affordances are dynamically coupled with bidirectional causality. In dance, martial arts, or team sports agents strategically comodulate each other's affordances while pursuing their aims. In Aikido, where agents try to break their opponents' balance, this trade-off globally approximates a zero-sum game-the better A's affordances are, the lousier B's affordances get. The agents are subject to ceaseless cross-causation in this shared field. They seek to obstruct their opponents' options while strategically enabling, augmenting, and sculpting their own by employing subtle perceptual manipulation skills, redirecting force, brinkmanship, and switching techniques opportunistically. To overcome static views, we conceptualize affordances as cascading and having fluid onsets; we also identify nested affordances in goal hierarchies and describe a spectrum of affordance functions. Ultimately, we suggest rethinking the ontology of affordances as being sensitive to dynamic engagements, hence defined relative to interpersonal emergence.
\end{abstract}

\section{Introduction}

This article applies the theory of affordances to settings of coregulative interaction. We specifically propose to think through the lens of interaction dynamics when two people strategically influence or change each other's affordances in real time, focusing on how antagonistic aims put their stamp on this. The martial arts practice of Aikido is used as an extended ethnographical example, although we draw brief comparisons to cooperative interaction skills.

Scholarship inspired by J. J. Gibson is showing considerable interest in multiagent environments and interactive behavioral dynamics (Warren, 2006), which underlie everyday social activities (Fusaroli, Rączaszek-Leonardi, \& Tylén, 2014; Marsh, 2015) but also decision making in domains such as soccer, basketball, boxing, social dances (Araújo, Davids, \& Hristovski, 2006; Bourbousson, Sève, \& McGarry, 2010a, 2010b; Esteves, de Oliveira, \& Araújo, 2011; Hristovski, Davids, \& Araújo, 2006; Kimmel, 2012; Kimmel \& Preuschl, 2015; Passos, Davids, \& Chow, 2016; Torrents, Hristovski, Coterón, \& Ric, 2016; Travassos et al., 2012), and robotics (Horton, Chakraborty, \& St. Amant, 2012; Ibañez-Gijon, Diaz, Lobo, \& Jacobs, 2013). In behavioral dynamics, due to real-time coupling between bodies, a new decision opportunity presents itself frequently. In dance and high-paced sports this can be up to

CONTACT Michael Kimmel michael.kimmel@univie.ac.at @ Schallergasse 39/30, A-1120 Vienna, Austria.

Color versions of one or more of the figures in the article can be found online at www.tandfonline.com/heco.

(c) 2018 Michael Kimmel and Christian R. Rogler. Published with license by Taylor \& Francis Group, LLC

This is an Open Access article distributed under the terms of the Creative Commons Attribution License (http://creativecommons.org/licenses/ by/4.0/), which permits unrestricted use, distribution, and reproduction in any medium, provided the original work is properly cited. 
several times a second. To succeed with this, agents must source cues from other agents whom they supply with cues in return. Typically, the behavioral dynamics are not scripted. The event is only globally specified or wholly unplanned; it takes on shape through reciprocal causation between agents (cf. coregulation in Fogel, 1993; participatory sense making in Di Paolo \& De Jaegher, 2007; Froese \& Fuchs, 2012; Torrance \& Froese, 2011). Agents shape and are shaped by smoothly adapting to each other's ongoing actions and the environment. As this embodied dialogue unfolds, a stream of transient perceptual configurations offers guidance. That is, actions are selected, modulated, switched, and terminated based on evolving interactional contingencies (McGann \& De Jaegher, 2009), which are drawn from spatiotemporal information such as geometry between the bodies or relative timing.

The associated empirical challenge is that such coregulated perception-action streams (a) are tightly interwoven and difficult to dissect, (b) involve highly task- and phase-specific sensorimotor skills, and (c) generate myriad alternative interpersonal dynamics. To address these challenges we report on selected data from a wider project tapping into first-person practitioner know-how. We applied special dialogic interviewing techniques, which allow both learners and seasoned experts to verbalize what usually remains implicit about their sensorimotor and strategic skills. ${ }^{1}$ For a more comprehensive introduction we refer the reader to a companion paper (Kimmel \& Rogler, 2018).

\section{Affordances in skillful interaction}

Affordances are informational pointers to action options, a well-publicized notion (Gibson, 1979/1986; Reed, 1996). In a first pass, we define affordances as a skilled agent's domain-relevant "perceivables" 2 that bear task-strategic information and have some sort of demand characteristics somewhere on the gamut between (even physically) compelling, optional, so-so, unattractive, or simply informing of momentarily undesirable but perhaps later feasible options. As we show, affordances can be immediate, gradually emergent, or only usable given preparatory actions, clear or fuzzy, and either accurate or misleading. In principle, affordances constitute a viable entry point for modeling the crisscrossing sensorimotor contingencies that drive interpersonal dynamics. Fajen, Riley, and Turvey (2009) suggested that affordances could provide "a functional semantics" for team sports and related interactive practices. We agree but emphasize that several theoretical complexities must be addressed.

\footnotetext{
${ }^{1}$ Explication interviewing was used in 18 retrospective interviews with learners of 3-11 years of training and 12 think-alouds with third to sixth dans, that is, expert ranks one typically receives after 15 to 35 years of training. Explication interviewing is a phenomenological method that uses dialogical probes to arrest the informant's attention, which allows informants to zoom in on their experience (Petitmengin, 2006). The interviewer's task is to encourage a mindful state, thus making the respondent bodily aware yet reflexive too. The specific procedure of explication sessions was to ask the practitioners to intuitively parse an interaction of perhaps 1.5 to 4 seconds, construct a timeline, and then zoom in on "thin slices" of approximately half a second for detailed inspection. The procedure is incident-based and highly specific with regard to sensory triggers, know-how regarding active perceptual probing (dynamic touch, etc.), who perceived what when, how agents reciprocally trigger each other (see Figure 1), and how perception shapes action strategies. It also allows exploring action imagery, the span of decision windows, and possible action alternatives. Furthermore, note that ethnographic data guided the process throughout, which came from C. Rogler's participant observation and Aikido practice diary kept over 2 years.

${ }^{2}$ Although it is probably a moot point whether affordances ontologically exist when not presently perceived, methodological considerations suggest great caution concerning speculative or anecdotally based existence claims. In view of context effects, skill effects, interactivity effects, and nonlinear cross-catalysis between parameters in a complex interaction setting, we deem it risky to generalize. Rather we emphasize the importance of carefully reconstructing unique interaction dynamics based on "Who perceives what when?" and "Who decides and executes what when?"
} 


\section{Skill, context, and dynamicity}

Ethnographic approaches remind us that affordances are task and skill related (Costall, 2012; Ingold, 2000; Kimmel, 2012) and embedded in a world of social practice (Rietveld \& Kiverstein, 2014; van Dijk \& Rietveld, 2017) too, including wider behavior settings (Heft, 2001, 2007), embedding values and interests (Hodges, 2009), and alternative choices contained within the wider "affordance landscape" (Bruineberg \& Rietveld 2014). What complexities this implies for the empirical study and descriptive terminology of a sophisticated skill domain becomes apparent in our case study.

Moreover, despite the fundamental posit that affordances evolve relationally between agents and their environment, the resulting dynamicity is often underplayed. As Chemero (2009, p. 150) critically noted, ecological psychologists "define affordances statically" Many affordances are transient; they evolve and devolve again. Fajen et al. (2009, p. 89) dubbed them "quicksilvery" (p. 89). This suggests we should investigate the micro-dynamics of their arising and their dependency on strategic action priors (including, e.g., micro-actions that create, preserve, or heighten an affordance) as well as enabling macro-parameters set in advance. A dynamic conception must also recognize the frequently path-dependent logic that Gaver (1991) usefully termed sequential affordances. Certain affordances do not reveal themselves unless others have been acted on. Action cascades with an explorative (or even expectable) sequentiality abound, some of which are additionally constrained by a hierarchical task structure.

\section{Interaction}

More generally, a mature interactionist outlook depends on the investigation of social affordances as part of interagent dynamics. Many otherwise insightful experimental paradigms fall short of this because they focus on social affordances perceived prior to interaction. They discuss oneoff exposure effects to social stimuli, for example informational variables specifying age, gender, mood, or vulnerability (e.g., Marsh, 2015; McArthur \& Baron, 1983) or validate the ability to perceive affordances of others (e.g., Mark, 2007), social object affordances (Schmidt, 2007), and affordances for joint action (e.g., Creem-Regehr, Gagnon, Geuss, \& Stefanucci, 2013; Davis, 2009; Davis, Riley, Shockley, \& Cummins-Sebree, 2010). A more dynamic paradigm would look at how such moments of affordance recognition lead to actions that in turn trigger reactions within an interagent dynamic. Fitting this job description, studies of dynamic decision making in field sports like rugby have emerged (e.g., Esteves et al., 2011; Passos, Cordovil, Fernandes, \& Barreiros, 2012; Travassos et al., 2012). These investigate percepts within rapid interaction dynamics where agents must respond momentarily to "context-dependent information fields" (Silva, Garganta, Araújo, Davids, \& Aguiar, 2013, p. 768) and, in part, model the unfolding perception-action cascades between agents. This sits well with the growing recognition that social affordances, as Hodges (2009) phrased it, arise from a "dialogical array" and an interest in how extended macroscopic action-systems create their own affordances (Richardson, Marsh, \& Baron, 2007). It also fits the broadening perspective on affordance-based "social synergies" (Marsh \& Meagher, 2016). Sustained interactivity is crucial for sensitizing infants to affordances (Nomikou \& Rohlfing, 2011; Zukow-Goldring, 2006), and guided apprenticeship educates attention later in life (Ingold, 2000). In fact, many useful affordances arise only interactively, that is, one needs to sustain an encounter to create feedback "as one goes along" through generative actions (Ballard, Hayhoe, Pook, \& Rao, 1997; Gray, 2004; Kirsh \& Maglio, 1994; Steffensen, 
2013) and strategic enactive probing (Kimmel, 2012). Affordances emerge dynamically as agents generate creative interactive solutions (Hristovski, Davids, \& Araújo, 2009; Kimmel, 2018; Torrents Martín, Ric, \& Hristovski, 2015). For example, small, dynamically introduced variations of a perceptual parameter can prompt the emergence of a novel mode of action (i.e., a new affordance) to existing ones and thus increase task entropy (Hristovski et al., 2006).

\section{Outlook and aims}

This brings us to our central theme: which affordances arise is not predictable alone from the combination of agent-side variables such a body size, strength, and skill or simple environmental variables. In much of the literature, an idealized fiction holds sway-applicable to interacting with artifacts or spaces-that a particular affordance reliably manifests in a given situation for an agent equipped with a specific body and specific abilities. Yet, it should be evident that the other person's intentions, values, and capabilities (see examples on postural and rapport skills in Kimmel, 2012, 2018) equally count as well as the other person's specific mode of responsiveness and strategy.

As a direct result of this, whether a particular interactive affordance manifests depends on situated modes of engagement. Think of the difference between when a tentative and playful martial artist meets a self-assured and confrontational opponent as opposed to when the same person meets someone of her own ilk. Or think of the difference between two consummate improvisers, one improviser and a person exclusively relying on "ready-mades," and two persons of the latter type. Depending on how strategies and intentions of two agents mix, radically different courses of interaction result. When agents $A$ and $B$ both enact their chosen modes of engagement, specific interactivity-based affordances emerge from the collective dynamic. As an aspect of this, a sustained engagement with dynamic coactions of others may be needed for affordances to arise in the first place. We later show that in Aikido a series of prior actions is needed before one can even consider fully defeating an opponent (see section "Aims and structure and Enabling affordances across transitions"). Thus, affordances may be contingent on cascading interaction dynamics, each with their particular micro-histories.

The deeper consideration here is that affordances are sensitive to mutually responsive engagements, which differ from interactions with spaces and objects in a principled way. A new layer of reciprocal micro-dynamics arises. For example, Aikido attackers can be subtly nudged to do something to their later detriment (see section "Enabling affordances across transitions"), false information can be introduced while the action is going on (see section "False affordances and brinkmanship"), and affordances can be downscaled before being ripe for the reaping (see section "The interactive field: zero-sum coupling, comodulation, and affordance dynamics") or flipped into something quite different on the go (see section "Affordance surfing"). When two agents engage at the same time, especially within an adversarial setting, this can result in complex dynamics. As agents interact continuously, so do their affordances. For all these reasons, the proper unit of analysis must be the dynamically evolving agent-agent-environment triad (see section "Towards a triadic ontology").

\section{How Aikido is practiced}

Aikido ("the way of harmonizing energy") is a soft martial art practiced worldwide; it was originally developed and taught in Japan by Morihei Ueshiba from the 1920s onward. 


\section{Aims and structure}

Aikido emphasizes reciprocity, noncompetitiveness, and renouncing violence. "Ai" means to harmonize or act reciprocally. Aikido is understood by many as a mindfulness practice, although it remains rooted in Samurai cutting techniques. The objective is to defend oneself against grabbing, thrusting, striking, knife, sword, or staff/spear attacks. A defender executes a series of well-flowing action elements aimed at breaking an attacker's balance without injury while remaining poised in axis and ready to take on further attackers. In this short bout of about 2-3 seconds, the defender seeks to (a) step out of the line of an attack either to the front or backside of the attacker (unless she executes a linear counterattack through a quick punch); (b) take up the blow, thrust, or grab by blending with the opponent's aggressive energy; and (c) disperse the attacker's energy in circles and spirals, turning it against her to break her balance. Figure 1 shows how the interception takes up the blow before the attacker's hand reaches its apex. To prevent the attacker from still cutting downward with force, the defender must also have stepped out of the line of attack before contact. Now a defensive lever can be executed. The defender moves past the attacker with a second step. This involves one or occasionally two direction changes, usually at velocity minima that allow various possible continuations. Once the attacker's balance is broken the defender can optionally guide the opponent to the ground and apply a fixation.

As the agents begin to engage the collective dynamic is poised in a symmetric state for a moment that is pregnant with multiple possibilities. Only as one agent gains dominance is this symmetry broken. This symmetry breaking (Bourbousson et al., 2010b; Kelso, 1995; Richardson, Washburn, Harrison, \& Kallen, 2016; Yamamoto, Okumura, Yokoyama, \& Kijima, 2016) designates a point of no return after which the defeated party cannot recapture the initiative. The underlying physicality of this is interesting: defenders must extend their senses via the arm and the tactile interface down into the opponent's body center and support on the ground. As a lever is locked or a throw initiated the defender gains full control over the attacker's center of gravity and constrains most other degrees of freedom. In a sense, the defender establishes a macro-system consisting of two bodies but behaving as one physical entity. A low-dimensional joint system is created. By extending physical control into the attacker, her autonomy is lost and she is physically compelled to follow the defender's movement.

Structurally, every individual Aikido bout consists of between three and four distinct movement phases. (An exceptional maximum of five phases is the case for special techniques in which the lever execution involves changing direction twice.) Every phase involves a very

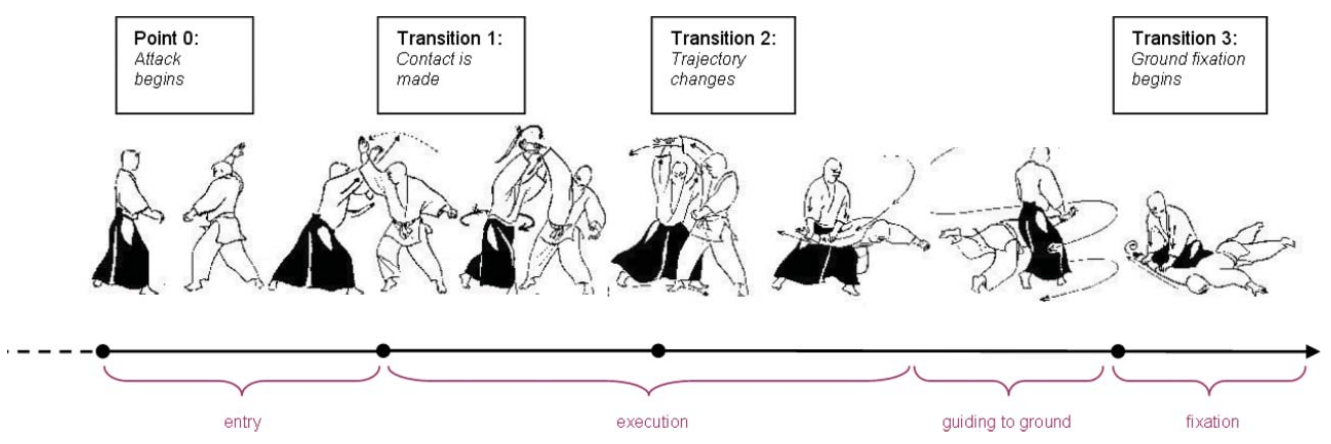

Figure 1. Structure of a bout exemplified through the iyyko technique (images @ Westbrook \& Ratti, 2001). 
short action like punching (tsuki), striking from above (shomen) or a defensive rotational step (tenkan), direct stepping toward the opponent (irimi), taking up a blow, lever handgrips (e.g., ikkyo, nikyo, sankyo, yonko, gokyo) or throws (e.g., irimi nage, shihō nage, kaiten nage, koshi nage, kokyu nage), and rolling safely onto the Aikido mat (ukemi). The individual elements should be connected fluidly, although transition points make it tricky for a defender to control the degrees of freedom enough: this is where most countertechniques set in once a "gap" opens, that is, the attacker can retake the initiative when the defender is careless.

The defender must be prepared, have a well-grounded stance, distribute muscle tone well, and move with the axis aligned and erect. She should be attentionally prepared to intercept in a way that adapts to the attacker's specific spacing and speed. Defenders abide by specific perceptual and control principles, notably by finding a good timing-distance trade-off ( $m a^{\prime}{ }^{\prime} i$ ) for effectiveness without endangering themselves (cf. Caron, Coey, Dhaim, \& Schmidt, 2017) and by finding the right geometry.

Although training differs from street fighting, both require the application of a certain amount of force. An attack with sham force would obviate practice in a functional sense, as energy to convert into a defense would be unavailable. A good defender may let the energy accrue somewhat before intercepting and turning it against the attacker. Thus, it should be possible to train a defense realistically so that the costs of failure become apparent. Yet, a respectful and learning-oriented ethos reigns in the background, and more advanced practitioners may subtly assist their less experienced opponents. A "we" attitude (Gallotti \& Frith, 2013) of respect, safety, and commitment to the spirit of Aikido is called for. Note that advanced practitioners may moderately help a novice by scaling down force, foregoing a timing advantage (e.g., by not making use of prospective information for early counteraction), or sticking with the practiced technique even when a mistake invites a more effective improvised variant. Similarly, experts may create an accepting and relaxed climate of practice that helps the opponent optimize her "grammar" and awareness to mutual practice benefit.

\section{Modes of adaptivity}

Aikido is about training how to best adapt to a unique encounter and its emergent configurational and temporal details, albeit exhibiting coregulation to different (modality-specific) degrees: In training, standard techniques are practiced by taking turns between attacker and defender roles, whereas advanced practitioners also train free responses to specific attacks (jiyu waza) or mutually practice freestyle (randori). In techniques called out by the teacher the functional principle of defense-a specific arm lever or throw-to be practiced is known beforehand but leaves much coregulative leeway in the specifics. The defender's precise response timing, trajectory, and technical details respond to interactional contingencies gleaned from the attacker's relative geometry, speed, power, exact timing, and so on. In freestyle practice, experts choose from a repertoire of several dozens of techniques or even create their own hybrids. Here, coregulation occurs at its fullest, by improvising both the "how" and the "what."

Let's assume a preferred defensive technique has been announced by the teacher or is mentally self-selected. In the ideal case everything is as expected: feedback conforms to the expected reference of correctness appropriate to the particular Aikido technique. This is defined by phase-specific control laws (Warren, 2006) specified through the distance, angle, speed, action contour, and force profile. In a slightly less ideal scenario, minor dynamic repairs are needed to 
keep the intended defense intact, often by activating extra muscle synergies, a slightly changed angle, a small extra sliding step, or a firmer grip. The transitions from one phase to the next happen as expected, however.

A slightly more incisive adaptation occurs when some unfortunate occurrence or imprecision calls for, say, adding a deflective punch or adapting one's stance, although the main technique remains within the general technical principle, say the ikkyo wrist lever from Figure 1. In early phases of approach even one's trajectory can be adapted as one can execute the ikkyo technique on the attacker's front and back. The continuation remains partly the same in terms of technique, but the original spacing preference displays no optimal affordance anymore. Such an early adaptation results when interbody geometry or timing are a bit off or from an unexpected second attacker. (Defenders want to be poised to intercept the second person or even throw the first opponent against the second.)

A yet more adaptivity-demanding case occurs after contact if the ikkyo lever meets with resistance from the opponent. Now, the defender may switch to another lever to preserve the key principle never to work directly against someone's energy. Basically, when a defender blocks in upward direction one utilizes her downward energy, when she resists to the left one moves to the right. Any attacker resisting the defense ipso facto creates alternative continuation affordances.

Once Aikido practitioners have learned to rapidly adapt to various contingencies, they can fully improvise their defense. Only as contact with the attacker is made or briefly before is a specific defense selected. The same ad hoc decision principle applies later in a bout. The freestyle exercises (randori) train the use of emergent affordances of any sort. Scores of continuations can be chosen on the spur of the moment (although one may get by with a handful).

From the attacker's viewpoint, a range of options present themselves when the attack starts, but if the defense prevails they rapidly dwindle away. Bodily degrees of freedom are now controlled by the defender and the main concern becomes how to fall without injury. However, as defenders may make mistakes or be inattentive, attackers who remain highly sensitive to gaps left open can retake the initiative. In such countertechniques the roles are switched on-the-fly.

\section{Aikido affordances}

To practitioners, every situation on the training mat has a specific "demand character" ("Aufforderungscharakter" after Kurt Lewin). Because interaction is coregulative practitioners must pay attention to the unfolding stream of affordances at every moment. Each moment is filled with attractive options as well as risky or downright detrimental ones. They strive to create, improve, or preserve phase-specific affordances of quality while being sensitive to how opponents curb these, and they remain attentive to alternatives when affordances dwindle. We now introduce a host of specifying concepts to apply affordance parlance to a naturalistic setting such as Aikido.

\section{Practice modes, skill levels, and general agent strategies}

What makes a good Aikido affordance? Aikido is quite unlike, say, pair dance, where any option striking the leader's fancy is tried out for the fun of it and any "good-enough" affordance qualifies. In martial arts efficiency is what counts, and typically only the affordance of 
best quality gets selected concerning the ease-efficiency ratio. After all, Aikido is modeled after Samurai combat, where choosing a second-best option would maybe result in death. Many experts report a clear single option coming to mind (compare decision research by Klein, 1998). ${ }^{3}$ Note that the inherent affordance "density" at a specific point also depends on the subsequence of an Aikido bout, as options tend to decrease in the later stages as a consequence of path-dependency.

Bruineberg and Rietveld (2014, p. 5) differentiate a wider "landscape of affordances" characteristic of a niche (such as Aikido) and a "field of affordances" that stands out as relevant for a given situation. Which potential Aikido affordances stand out as presently meaningful is relative to the chosen practice modality and behavior setting (Heft, 2001), a mix of perceived context, intentions, and expertise. Someone practicing in a freestyle randori frame will perceive far more relevant affordances than someone practicing a particular technique, which imposes a filter. Someone currently working on a technical finesse will disregard easier alternatives but perhaps scale their attention up to perceive details of the situation and so perceive affordances more granularly. Every Aikido situation highlights different facets depending on training aims, such as, "I would like to practice my sensory acuity today" or "I would like to focus on variability and leave the beaten path."

The role of skill and further individual variables comes into the picture through effectivities, the subject-sided counterpart of affordances (Turvey, 1992): a person's strength, height, weight, balance, dexterity, perceptual acuity, and momentary training state all shape what can be easily acted on. Effectivities codetermine what kinds of affordances of the Aikido system are perceivable and/or available to someone's skills. (Skills for recognizing and actualizing the action may not always be equally developed: for example, some novices possess perceptual acuity regarding the information but are too unskilled or slow to act on it.) Specifically, the degree of expertise shapes both the breadth of the general affordance landscape and the momentary affordance field a practitioner perceives, the sum total of available "doables." Despite intuitive preferences, a fourth, fifth, or sixth dan, that is, a high rank, might perceive literally dozens of different affordances where a novice perceives one or two at best. The number of competing affordances grows with time, but perhaps so does subjective clarity about which among them is best, so they can become an "intelligent reflex" (Sutton, McIlwain, Christensen, \& Geeves, 2011). Meanwhile, as one learns, many possible options may be felt as being almost but not really good enough; learners may still need to develop their skills for an affordance to become fully available to them.

Affordances notably depend on perceptual skills. Practitioners probe affordances through an active sensory focus (Degenaar \& O'Regan, 2017), especially by extending their proprioception toward the body center of the opponent. Specific ways of touching that notably allow an open energy flow and relaxed muscles provide for dynamic touch (Turvey \& Carello, 2011) that doesn't smother the energy. These epistemic actions (Kirsh \& Maglio, 1994) are embedded in pragmatic actions and generate sufficient information. Concerning gaze, experts report a refined ability to notice prospective giveaway signals very early in the approaching opponent. Opponent actions can then be preemptively thwarted, for example,

\footnotetext{
${ }^{3}$ Interestingly, some aspects such as which side to step out of line may be rather decisionistically chosen — without manifest efficiency gradients yet-whereas later preferences spring from the resulting interaction pattern after physical contact.
} 
when a quick irimi slide-step quickly reaches an opponent still lifting her arm for a shomen, a blow from above. ${ }^{4}$

Meanwhile, different practitioners seem to set a different emphasis on their affordancerelated strategies: whereas some invest themselves in powerful manipulative skills, othersoften lighter persons-focus on perceptual finesse (micro-sensation skills) and improvisational openness to whatever the opponent offers. The former strategy amounts to actively optimizing the affordance quality of a desired option, whereas the latter strategy optimizes affordance density, that is, agents keep poised for as many options as possible (i.e., maintain their metastability), hone their ability to take advantage of any minute contingency, and deal with surprises through lightning-quick reactivity.

\section{Enablement through a prepared body: Proto-affordances}

All complex skill systems operate at multiple timescales (Kimmel, 2017). Foregrounded micro-skills are only possible against the backdrop of a prepared body. ${ }^{5}$ Surprisingly, scholarship has largely neglected the fact that permanent enabling activities provide a highly domain-specific type of skilled effectivity, which may be described as proto-affordances. Phenomenologically, this notion corresponds to a subjective feeling of generalized enablement for the full range of domain-specific tasks. Claiming that proto-affordances are required highlights hidden structures of preenablement and calls into question the naive model in which skillful action just kicks in from scratch, and that's that.

Specifically, enabling habitual activities and somatic modes are activated when one begins to practice Aikido. They set appropriate constraints for action-readiness as well as communication-readiness for the entire range of tasks that may occur in the domain. Kimmel (2012, 2016) speaks of domain-specific "grammar," which when adhered to, supplies such proto-affordances. Grammar is tantamount to the body organization that poises an agent for a variety of contingencies and provides a neutral state (metastability) that allows operating in an open task space. Grammar is thus the basis for flexibility. Basic degrees of freedom (Bernstein, 1967, 1996) are permanently reduced and (a) enable situated actions to kick in immediately while (b) embodying specific disciplinary constraints like axial alignment. General "precalibrations" that lend Aikido its recognizable style include upright alignment and well-groundedness (shisei), balance $(k u)$, muscle semirelaxation (kincho), calm breath, attention, and a soft-focus or "empty" gaze that allows awareness of the whole field of vision (metsuke). In addition, the skill of constructing interbody musculoskeletal chains and connecting with the opponent's body center can be understood as an interpersonal habit that is always active after contact.

Proto-affordances contribute to more situated tasks (with full affordances) yet leave a broad range of options open for specification. When Aikido practitioners lose posture, alignment, or tone most situated affordances will immediately vanish. The agent is not poised for

\footnotetext{
${ }^{4}$ As the flip side of this, agents may also be aware of what could give opponents a prospective affordance. Because roles are switched frequently agents are rather familiar with how the scenario appears to opponents (allocentric perspective; Mark, 2007). This mental role reversal, as it were, help agents avoid telltale signals to avoid accidental enablement of their opponents.

${ }^{5}$ This relates to the emphasis in dynamic systems approaches on multiple timescales of interaction (Dumas, Kelso, \& Nadel, 2014; Eiler, Kallen, Harrison, \& Richardson, 2013). Permanent "grammar" skills are one important aspect of how the higher timescale becomes effective, although other, more interactive aspects like training history with a partner also belong in this category.
} 
action anymore and information channels are disconnected. Phenomenologically, protoaffordances manifest as a feel of general action-readiness and physical enablement for a large range of possible actions. Proto-affordances are a means of orienting toward the affordance landscape of Aikido as a whole. By preparing the ground, they constitute a necessary condition for the micro-actions that can then be fleshed out in context to be rapid and precise.

\section{Affordance types in hierarchical tasks}

Moving now to "full" affordances, we must distinguish the omnipresent execution-related affordances from affordances signaling continuation choices only at selected decision points. Thus, micro-affordances used to control ongoing actions contrast with main affordances when a new action element begins (Kimmel, 2012), where agents must (a) orient toward information specifying continuation options, (b) select one of the options, and (c) manage a good transition. Micro-affordances, in more scripted training, dominate in awareness over choice-related affordances: because the technical trajectory has been selected before, no rerouting is expected and fine-tuning suffices. By contrast, freestyle practice keeps agents perceptually open to a range of trajectories, so main affordances for continuation are simultaneously monitored. Normally one would assume that main affordances are considerably less frequent and appear only at the major junctures of a technique, as shown in Figure 1. However, with top-level practitioners the choice-related main affordances that novices experience only at 2-3 points come to populate even the gaps between junctures while decision windows also widen. Mastery thus multiplies perceived affordance density. It almost seems as though many micro-affordances may become choice-related (main) affordance, provided one has a good command of action skills and a broad technical repertoire that can fit virtually every situation. (However, further data is needed to ascertain whether masters can begin new trajectories just anywhere or if their relevant windows of opportunity simply expand greatly.) Presumably the perceptual phenomenology of experts also becomes highly "thin sliced" and hereby enhances immediate responsiveness, as a study with experts of Contact Improvisation dance (Kimmel, Hristova, \& Kussmaul, 2018) as well as studies on sports (Sutton, 2007) suggest. Subjective time expands and finer structures become discernible in what is objectively a quite short action trajectory.

Furthermore, affordance theory needs to come to terms with the multiphasic nature of Aikido encounters. A whole chain of action elements is needed to break the other's balance, with subactions obeying a cumulative causality. That is, elements build on each other and only make sense relative to a good integral structure. Functionally, you can only throw the attacker to the mat after having quickly come forward, taken up the attack with the appropriate evasive sidestep, then initiating a lever or throw technique, completing it with a second step and, optionally, a follow-up ground fixation. No opponent can be toppled immediately but only through a series of intermediate actions. (This cumulativity contrasts with domains like Tango dancing, for instance, where every step is logically relatively independent, as no goal constraints exist beyond creativity and good rapport.) All nested subactions of a bout point in a single direction, toward ending the interaction by defeat. Earlier phases causally enable the later ones, somewhat akin to Gaver's (1991) sequential affordances. This notion was coined for situations in which one affordance triggers an action, whereby a further interesting affordance is revealed. All Aikido unfolds like this. Another aspect of Gaver's definition applies less generally: in freestyle randori the revealed next 
affordances may be unexpected, whereas especially scripted Aikido training tends to produce expectable affordances, which nonetheless need to be revealed before becoming functionally available. ${ }^{6}$

We propose to understand Aikido as involving three hierarchical levels of action. Every bout is globally oriented toward the pivotal event of breaking the opponent's balance (which is equal to symmetry breaking in the collective dynamic; see section "Aims and structure"). Over a bout's phases new subactions set in around transitions where action velocity drops to a minimum and direction changes. For instance, a straight sliding step (irimi) with arm blockage by one hand morphs into a tenkan rotational step with an arm lever where the second hand also comes into action. Transitions need to be carefully controlled, as they give the opponent a possible moment of respite and counterinitiative. At the lowest level each subaction, say the tenkan rotation and associate arm action, needs to be controlled.

Consequently, at the level of perception Aikido practitioners simultaneously orient toward three timescales of affordances. First, throughout the whole bout, a global affordance defines the task as a whole and signals how close one is to prevailing. Second, upon their completion a transitional or main affordance appears at key junctures where new action elements must set in and where a decision window is located. Third, short-lived micro-affordances (Kimmel, 2012) support the control of micro-actions. Each level has its own perceptual signatures:

- Global task affordances: In view of the cumulative goal of toppling the opponent, practitioners report being able to permanently gauge how far or near they are from breaking the opponent's balance. The information is contained in how upright the body axis is and how far the opponent is from this ideal, a differential that can be acutely sensed at any point. This provides, figuratively speaking, a perceptual "chance-o-meter" summing up the interaction history so far. Another global principle, especially when a practitioner chooses the preferred technique only as the interaction progresses, is minimal resistance. The affordance-related signature skill of Aikido is to blend with the attacker's energy and find the path of least resistance against it while dispersing this energy. A final (and related) kind of global information concerns flow properties of a well-executed technique, a point that directly relates to our next category.

- Transitional main affordances (junctures, continuation options): A specific type of affordance marks transitions between elements and points to possible continuations. In martial arts, transitions between motor subunits are critical moments laden with the risk of the opponent gaining the upper hand, and thus also define intermediate checkpoints. An upcoming transition is signaled by characteristic informational pointers of the last motor unit's completion and the next step beginning (e.g., the current motion exhausting itself, tactile contact, or force-resistance). Further informational pointers inform agents about alternative continuations and the possibility space of follow-up movements that are afforded by the constellation. This information is contained in the degrees of freedom the Aikido practitioners feel via pressure and resistance signatures,

\footnotetext{
${ }^{6}$ Given the frequency of scripted Aikido training, this suggests affordance-related expectations can become embedded into a complex event representation used to understand causal dependencies and can guide a multiphasic action (Hommel \& Nattkemper, 2011). Although many teachers warn against too rigid scripts and encourage throwing them overboard at some point, quite a few practitioners report these scripts.
} 
which indicate open energy paths to follow. To be selected, an open path must of course also match familiar repertoire structures.

- Micro-affordances (control of elements): In completing a subaction, micro-affordances afford feedback-based control of its precision and dynamics. In other words, between transitions there are small stretches of time where the completion of initiated action-units has priority and neither major trajectory changes nor notable choices among alternatives are afforded. Micro-affordances confirm the ongoing action or suggest dynamic repairs in case of an "is-ought" gap (cf. Wolpert et al., 2003). The multisensory mix that specifies micro-affordances differs with various different movement elements and with task-phases. To illustrate phase-specificity, an attacker initially orients toward affordances for striking or holding, but when this fails the intention becomes to restabilize against a defense, and if that also fails safe falling is the aim (ukemi).

To recap, a good behavioral arc (Kimmel, 2016) must conform to perceptual guidance at multiple timescales. The current action, past actions, and prospective futures must create a well-flowing whole with well-allotted parts. Can affordance-based guidance explain how such a multiphasic action is controlled? Phrased in motor control terms, can closed loop mechanisms alone do the job of creating a complex hierarchically organized defense? Dreyfus (2007, p. 1147) and Bruineberg and Rietveld (2014) draw on Merleau-Ponty to model skilled guidance of action as a continuous maintenance of "maximum grip" on a moment-by-moment basis. The hypothesis is that agents can locally maximize their grip on a situation by operating on a gradient that, at each moment, poises the system to minimize future surprise, uncertainty, and risk. Can local grip maximization provide direction within a hierarchically organized task? We believe a maximum grip account may explain multistage causality with nested levels of control rather nicely. It simply requires that agents orient towards feedback at multiple timescales. A sensitivity for global constraints must inform every moment, that is, every subaction must simultaneously conform to the longer term action logic. Specifically, global success is ensured when one's own axis is kept more stable than the opponent's axis, i.e. when a stability differential can be felt. In this way futures can constrain presently afforded options (cf. Pezzulo, Barca, Bocconi, \& Borghi, 2010) without representational anticipations, but by ensuring good higher timescale dynamics.

However, even from a purely logical viewpoint, a maximum grip solution to cumulative and hierarchical interaction works if, and only if, specific enough information-based constraints are available on parallel timescales. This might be the case in Aikido. We have specified what these constraints could be, although this falls short of a full model or proof that maximum grip at multiple timescales is sufficient. Also, we remain skeptical about whether this can explain complex interaction skills across the board (see Kimmel, 2018 on improvisational creativity).

\section{Dynamic micro-scaling}

Affordances are scalar in a double sense. First, viewed in micro-time, many affordances are gradual in their perceptual onset. Around a critical threshold of signal strength affordances remain barely perceptible. That is, sometimes a hint of an action option emerges that one can only detect with an extra amount of concentration. Second, even when affordances present themselves right away with clear signal strength, how attractive an option is judged to be 
may only be middling. That is, the degree of perceived "doability" can be compelling, strong, barely sufficient, dubious, or "good, but out of my league." When the "doability"-specifying sensory parameters hover in the optimal region (Warren, 1984), the task seems easy to realize, whereas values near the critical threshold seem difficult or dicey. At any given moment, values of a parametric dimension range anywhere between critical and optimal.

In adversarial interactions such as Aikido opponents thwart your efforts, so that affordances become inherently precarious. Quality affordances are frequently not "just there"; as we have seen earlier, a demanding goal like safely throwing an opponent is a cumulative achievement. The same necessity of step-wise enablement applies when we zoom in: the consecutive elements of a defensive technique must be enabled by appropriately scaling the configuration prior to the action. Ideally this happens by precisely and effectively completing one phase and hereby producing the next phase's preconditions. Similarly, actions that enable affordances are needed when some still ambiguous situations display a hint of beckoning: "do something to fully manifest this option." Initially agents sense a main affordance through prospective micro-affordances (Ibañez-Gijon et al., 2013) that precede it, yet fully materialize the main affordance only through micro-actions that rescale the configuration. Hristovski et al. (2011, p. 199) speak of "creativity," which manifests "as the creation of affordances, i.e. opportunities and context for efficient action". 7

Scaling efforts may also be needed in the act itself when the opponent's concurrent efforts put pressure on you, for example, by mobilizing further muscle synergies or by increasing the precision of movement. To illustrate, let's take the moment of intercepting an attacker's blow when a defender moves out of the line of attack. Increasing the interbody angle makes the impinging force pass by and provides a safe and functional geometry for gripping the opponent's arm to begin a lever. If needed, the interbody angle can be further increased, the grip tightened, the lower arm rotated inside or outside for getting leverage, the hip rotated more, or the sliding step enlarged. Strategies are thus dynamically scalable in many micro-dimensions.

To conclude, these self-enabling actions scale up perceived potentials, which phenomenologically correspond to a feel of "improve me!" or they respond to a perceived threat to an existing action potential, which corresponds to a feel of "salvage me!" If the enablement works it can be felt as task-specific degrees of freedom growing.

\section{Enabling affordances across transitions}

Some strategic actions work at a remove. They are indirectly affordance-enabling and typically stretch across phase boundaries of the bout. A central skill to mention is that a defender may "invite" through her positioning a specific attack for which she is inwardly prepared. Hence, subtly manipulating an attacker can begin well before contact. For example, how you offer your palm to an opponent who grips you (more upward, perpendicular, or downward) depends on what technique you intend to do after contact. In case of a lever, practitioners typically choose the direction that leaves the arm's energy potential open for the specific

\footnotetext{
${ }^{7}$ We may elaborate on improvisation skills here. Two prerequisites were mentioned earlier, namely, temporally fine-grained perception and a sizeable action repertoire, to which we may add further skills: (a) In unfamiliar situations highly trained perceptual faculties allow integrating meaningful information, notably affordance-specifying invariants that tell them "what's going on" and "how to continue from here." (b) Experts also show capabilities for softly assembling novel action solutions on the spot based on a deeper biomechanical understanding of possibilities of toppling another body (e.g., one informant mentioned he uses four principles that allow subsuming all techniques he uses but also allow him to find hybrid solutions).
} 
lever type that is desired so they can still rotate the arm enough to send energy into the opponent's spine. Likewise, offering the hand at hip height best prepares for techniques where the arms remain at hip height after contact while offering at face height benefits techniques moving upward (e.g., kote gaeshi vs. ikkyo).

Defenders may also force the opponent to reactively create an affordance she desires down the line. In triggering such a sequential affordance, physical stimulation (e.g., pressure) forces the opponent to respond in ways enabling oneself. For instance, attackers may be forced to compromise their axis in a geometric constellation where reasserting the axis will inevitably spring another "trap." In the technique sanyko the defender waits for the attacker to try to reassert the axis as a kinetic precondition for initiating a lever.

To sum up the last two subsections, affordances in Aikido arise and persist only through proper micro-management of the dynamic. This suggests affordance theory should put a greater focus on strategic action priors, enabling micro-actions right before phase transitions, micro-actions that scale up fledgling affordances and micro-actions that preserve nascent affordances in the face of danger.

\section{False affordances and brinkmanship}

Let us now look in detail at the approach phase prior to symmetry breaking. Aikido experts possess skills for concealing signals that warn the opponent. Concealing means that, to have an edge in timing, it is imperative to avoid giveaway prospective affordances that would alert the opponent to adapt the attack. The defender encourages the attack's continuation, so the attacker's subjectively perceived affordances remain intact until it is too late. The attacker thinks she is doing well, and bang, all of a sudden she loses her balance. What contributes to this defensive skill? Experts try to keep their gaze empty to avoid cues that could orient their opponent. Sometimes, explicit distractions conceal (leg) movements; for example, a slap can disorient the opponent. Similarly, preparations for swift evasion from the line of attack may be invisibly initiated. Before contact (in the approach phase) the defender must not move too early. Instead defenders make subtle, imperceptible preparations for counteraction in the whole body and surreptitiously build up reaction potential that can then kick in suddenly. Actions are kept to minuscule but cumulating micro-preparations across the body to avoid one large giveaway movement. Upon contact, the defender "blends" with the attacker's incoming energy instead of using counterforce, an important principle. You don't put energy into the contact arm but instead prepare the body center and hips while keeping the arm in place. The resulting perceptual error of the attacker amounts to a false affordance for continuation (Gaver, 1991). The fact that perceived affordances can be more or less accurate is of critical relevance to martial arts strategies and probably many kinds of noncooperative interaction. Perceptual judgment error of others confers an advantage. Another perceptual manipulation mechanism that we documented in one informant was to "haze" the attacker by synchronizing and suddenly desynchronizing joint rhythms. The disoriented attacker loses her timing advantage and perceives affordances only blurrily.

Figure 2 visualizes how the sudden loss of perceived chances appears to an attacker. This reversal of fortunes partly owes to a kind of brinkmanship that may be a signature of antagonistic interactions of many sorts. As we just saw, while preparing for defense the defender leads the attacker on just enough to thwart the attack in time, a mini-max strategy. Unsurprisingly, antagonistic affordances frequently operate in the zone of the "barely possible" and are quickly lost when sustaining actions are a bit off or the opponent's counteractions increase a tad. Thus, the 


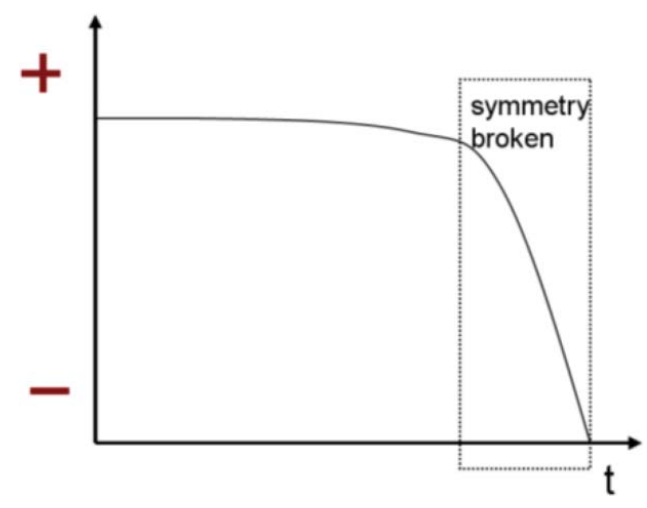

Figure 2. Sudden degradation of perceived chances.

interpersonal system occupies a metastable/critical position between at least two attractors at first, that is, bifurcations where minimal activities can tilt the dynamic either way (Bourbousson et al., 2010b; Harrison \& Stergiou, 2015; Pinder, Davids, \& Renshaw, 2012). Close to criticality, individual affordances are barely good enough. An attacker's affordance can therefore be tipped with minimal extra scaling by the defender, such that the symmetry is broken to the attacker's detriment. Criticality thus explains why a perceived good-enough affordance can reveal itself as false without warning. The affordance drops beneath the critical usability threshold because the defender concurrently messes with it and keeps these scaling actions hidden long enough. In a sense, the task's temporal extension as such is responsible: Viewed in micro-time, the scalarity of affordances in interaction streams allows for scaling up defensive actions while the attack is approaching but has not fully unfolded yet. It is interesting to note that two highly experienced informants (both sixth dans) emphasized how they move toward and joyfully linger in the zone where many things can happen, that is, in criticality. This is where novel and unexpected dynamics arise so that remaining in this zone allows them to explore and learn new things about microdynamics. (In another study we got similar comments from an expert dancer, whom we asked about techniques to boost joint creativity).

\section{The interactive field: Zero-sum coupling, comodulation, and affordance dynamics}

Thus, as the two Aikido practitioners are trying to thwart, counteract, or preempt each other's attempts, something peculiar happens. Affordances just being built up become subject to concurrent downscaling by the opponent (if this opponent is perceptive enough and quick enough). Taking away another person's affordances can happen through kinesthetic push-pull connections after contact but before that as well, through mere visual interaction. The simplest example is moving out of the line of attack while a punch is closing in. Through proper positioning masters can even downscale the opponent's affordances before the attack starts. It is for this reason, for example, that some famous anecdotes of two Aikido grand masters report that they endlessly circled, but no one ever attacked for lack of any perceived gap. ${ }^{8}$

\footnotetext{
${ }^{8}$ This example shows that self-organizing collective order can be created through visual information, without touching yet when both agents react in strategically lawful ways to one another (similar to chess champions who recognize when they need to give up several moves in advance).
} 
Thus, for good or ill, martial arts practitioners are linked in an interactive field, which connects their options dynamically. Globally, A's desirable affordances equal B's undesirable affordances. Once A and B begin to grapple and apply force, A's axis status inversely correlates with B's axis status. Whatever one person does to improve her axis impacts the other person's axis negatively. The opponent's affordances inversely covary with one's own (zerosum coupling). Actions that improve one's situation simultaneously serve to preempt, curb, redirect, or even destroy the opponent's nascent affordances before they are ripe for the reaping. We may term this real-time mechanism comodulation of affordances. This notion deserves more explanation. We argued earlier that affordances, viewed in micro-time, may not arise in an all-or-nothing fashion (simply present vs. simply absent) but can be augmentable and diminishable. This fact has interesting consequences for interaction: agents may choose to strategically shape each other's ecology while interacting, or even do so inadvertently. Arising affordances of agent A are subject to constant skillful modulations by agent B. That is, affordances in statu nascendi can slip or come to a standstill because the other person curbs one's ongoing attempts or, as we shall see later, even completely alters the situation. Comodulation explains a central strategic means in soft martial arts, which deprives the opponent of desirable options while improving one's own. (In fact opponents can interfere in efforts to prepare affordances as well.) To comodulate effectively Aikido experts develop skills for detecting subtle prospective affordances and cues where the opponent gives away her game through imprecision. With a gesture to the idea of niche construction in affordance theory (Heft, 2007; Rietveld \& Kiverstein, 2014) we might say that agents are trying to improve their "micro-niche" for the ongoing task, with strategies that shape both their own and the opponent's affordance field.

Notice that the general sort of interactive complexity is quite familiar from everyday settings, even in cooperative negotiations. Just think of situations when you begin to cross the street because you thought a car stopped for you, but you weren't exactly sure at first and move too hesitantly, so the driver thinks you are yielding right of way after all and accelerates; you both start at the same time and you paradoxically both end up braking again. An affordance is first suggested and then taken away interactively from you, and in the end both affordances briefly break down until a new negotiation starts.

From a general theoretical standpoint, we should emphasize that continuous, bidirectionally connected perception-action loops are the prerequisite for this sort of dynamic. Figure 3 visualizes how reciprocal comodulations generate specific affordance dynamics for the agents, with the red line standing for the affordance's quality and the dotted line for the critical threshold where the affordance vanishes:

1. We first contrast coregulative with non-coregulative interaction. An agent operating in a nonsentient environment furnishes the contrastive baseline condition where no reciprocal adaptation in real time occurs. Thus, neither static environments, for example, a door we walk through, nor moving objects intentionally adapt reciprocally to ongoing agent actions. For example, when someone dodges a falling rock, the rock does not alter its trajectory in response. The affordance for dodging appears for the agent when the rock starts falling and remains stable for a moment until the task is completed. The trajectory can be extrapolated in the short run. The perceived affordance is temporarily stable, so that particular actions can be decided in a one-shot manner. That is, no object intentionally adapts beyond its predictable physical reaction. 


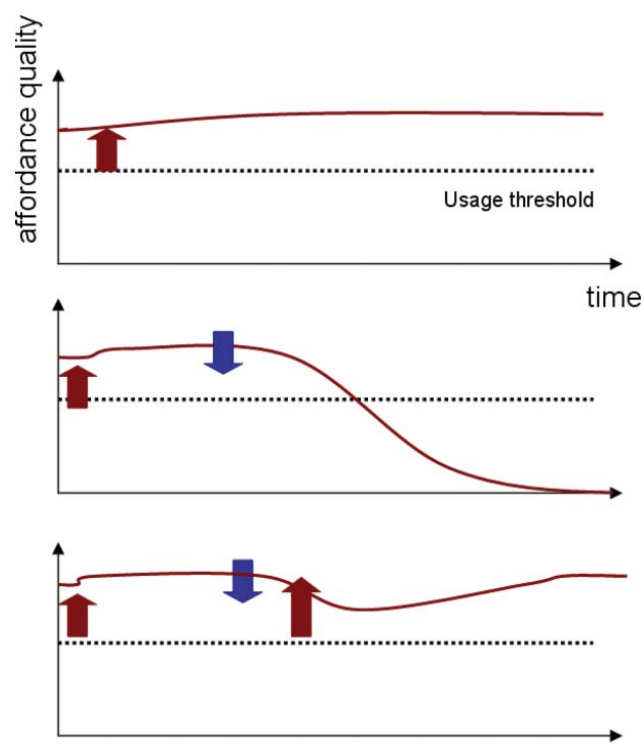

Figure 3. Comodulation and the resulting affordance dynamics. In the first scenario (top) the upward pointing arrow signifies action on a stable affordance, as when one interacts with objects. In the interpersonal scenarios (center, bottom) the downward pointing arrows signify counterattempts of B, which A resists in the third scenario, as indicated through the second upward arrow.

2. Things are different when the agent $A$ is faced with a coadapting agent $B$ with adversarial intent. Agent B, who detects A's too advantageous affordance, can diminish it through comodulating actions. A's affordance can hereby fall below its usage threshold and vanish. The agent cannot easily extrapolate the trajectory in micro-time because one cannot strictly predict another person's comodulations.

3. Now let us add as a final condition bidirectional coupling, a full coregulative loop. Unless one agent can conceal or falsify information, agent A will immediately notice the comodulations of $\mathrm{B}$ and can, in her turn, initiate protective actions for the desired affordance. In effect, two simultaneous reciprocal comodulations vie with each other. So why don't the opponents cancel their efforts out (i.e., infinite regress)? Why doesn't deadlock arise, as in the earlier example of the two infinitely circling Aikido grand masters? The answer is that normally one person turns out to be more skillful and that, for example, effects of early advance timing cannot be fully undone by the opponent at the high speed of combat.

Overall, of course, the simultaneous comodulation attempted by two agents can prompt quite different dynamics: fortunes may change repeatedly, B may overcome A immediately, or A counteracts the undesired comodulation in time and preserves her initial affordance (with a strategy like this the curve looks somewhat like that in scenario number 1 but for different reasons).

\section{Affordance surfing}

Another kind of complex interaction effect occurs when experienced Aikido practitioners "convert" dwindling changes into a different technique. They can, for example, suddenly 
turn a blocked or imprecise defensive technique into an advantage. More generally, affordance surfing, as one may call it, is a key strategic option in any type of improvisational interaction and produces a nonlinear shift in the global relation between agents. (This is possible because experts try to keep the dynamic in a zone where a sizeable affordance field relative to one's repertoire remains present.) Affordance surfing occurs when one agent sees fit to switch between action alternatives on-the-fly. The agent reparametrizes the task, typically because a desired main affordance is deteriorating and a nearby alternative continuation seems advisable or due to serendipity (in fields such as dance agents may even reparametrize the task out of curiosity or simply to explore creative options). To surf between affordances, Aikido practitioners must either feel the interaction is still sufficiently near to criticality or skillfully nudge the collective there. Even a slightly less nearby option may be reached with a quick, concentrated action or by skillfully exploiting short fluctuations in the force constellation (which depends as much on perceptual abilities for noticing the option as it does on technical skills for rapid rescaling).

Speaking in dynamic systems terms (Davids et al., 2014; Hristovski et al., 2011; Oullier \& Kelso, 2009) the more the interpersonal dynamics veer away from a primary attractor, another, better attractor beckons, which becomes attainable with a slight amount of extra effort and by skillfully exploiting the ongoing dynamics. Moving toward a new attractor lets the agent reassume energy optimality again, hence preserve maximum grip (see section "Affordance types in hierarchical tasks").

Affordance surfing frequently happens in response to an attacker who tries to forcefully resist the defensive technique or slip out of a hold. For example, at the point where the opponent almost escapes a lever one prepares an alternative trap. A path to a new technique opens by utilizing the attacker's counterforce. In Aikido, almost every kind of spacing or force someone uses can be turned to her disadvantage; for example, blocking a downward movement "invites" a technique that moves upward. Another motivation to flip actions occurs when you see a second attacker approaching. Practitioners change the technique's direction (i.e., adapt the extant main affordance) or switch to an alternative technique (i.e., a new main affordance) when redirecting is not possible. Yet another motivation for moderate action flipping is to repair one's own action, for example to make up for late timing. For example, by default practitioners prefer using the direct irimi sliding step to intercept a blow from above (shomen). This requires arriving at the interception point before the blow gains energy. When arriving late or if the attacker has built up more downward cutting force for whatever reasons the defender repairs this by doing a tenkan rotational step instead. A rotation moves the defender far enough out of line so the attacker's blow misses its target and more space is opened, which provides extra time for the defender to retake the initiative. Note that in such repairs the desired defensive technique with its characteristic body-center dynamics and functionality can be preserved. Adaptations of the footwork or of other subordinate means are sufficient for this. We refer readers who are interested in how the various Aikido strategies around spacing, timing, and force relations work to Kimmel and Rogler (2018).

A final, more radical kind of switching between proximal attractors occurs in Aikido countertechniques. Repeated switches of the dominant initiative characterize the dynamic here: The attacker, who notices a gap in the defense, retakes the initiative, most typically (but not always) through a new technique. An example is a striking attack, against which the defender initiates an imprecise ikkyo lever defense but fails to extend the arm fully. This 
allows the attacker to close in enough to slip behind the defender's hip and apply an aiki otoshi throw instead.

Again dynamic systems terminology helps to explain some details of affordance surfing. The collective is shifted from one of two intersecting attractor basins to the other. The defender A gets close to her desired attractor briefly but is nonetheless forcefully redirected to a repeller instead by attacker B. We might think of it as A lingering for too long in the outer vicinity of her preferred attractor where B can still make out a "channel" to a useable attractor in her own landscape. An imperfectly realized positive attractor of A moves a (quite different) positive attractor of B into reach, which ends up forcing A into her subjective repeller instead. This can happen only when A fails to fully control B's degrees of freedom. Open degrees of freedom create criticality again and allow "escaping" to a parallel attractor landscape.

The upshot is interesting. In the case of two Aikido practitioners their individual attractor landscapes multiply intersect while rarely presenting mirror-like inversions of one another. True, on the face of it the better you do, the worse your opponent does-yet the actual picture is more complex. So, due to nonlinear dynamic effects, we must now qualify what was said about Aikido being a global zero-sum game. Thus, a pretty good affordance status can still be flipped under certain circumstances. For instance, when someone initiates a countertechnique or switches from one defense to another, this can change the interbody configurations dramatically in a flash, together with functional options. All accessible affordances suddenly flip into a new "game." The underlying reason is that experts learn to exploit an intrinsic facet of complex interpersonal biomechanics: affordances do not always change linearly in biomechanic systems when these are composed of a complex array of synergies. An agent's affordances arise summarily from the organized interplay of multiple biomechanical elements. Yet a highly skilled opponent can reshape the entire high-level synergy by manipulating a well selected synergist at the right moment. Hereby even a position that is relatively far in one's own attractor basin, that is, close to one's success configuration, can remain assailable. When someone imperfectly realizes her attractor or fails to control countermodulations the opponent seeks points in space that are energetically open enough to allow for flipping the dynamics. We must therefore not think of the opponent's attractor landscape as precisely inverting one's own. It is preferable to (a) conceptualize two skill-, body-, and rolespecific affordance landscapes that intersect at specific points and (b) acknowledge that skilled agents actively seek opportunistic entry points into the larger basin around the opponent's desired attractor where the tables can be turned. One obvious reason the two landscapes are seldom mere inversions of one another relates to effectivities: every person has unique skills so that, especially in the tiny details, a particular ability on one agent's part can open an affordance even when the other part commits no actual mistake.

Another connection meets the eye here: Saltzman and colleagues usefully define tasks in terms of how state variables, that is, momentarily active degrees of freedom, relate to the (usually slower) parameter and graph dynamics of a task (Saltzman \& Caplan, 2015; Saltzman \& Munhall, 1992). What we term affordance surfing implies a mildly anomalous case in which parameters "change on a timescale comparable to, or even faster than, the corresponding state-variable's timescale," as happens when agents "switch from one target to another" (Saltzman, Nam, Goldstein, \& Byrd, 2006, p. 64). Affordance surfing can be interpreted as an agent's effort to reparametrize the task midway so as to improve her overall chances. Moreover, expressed in the parlance of state, parameter, and graph dynamics, 
Aikido countertechniques imply a sudden change in the graph itself because the roles are suddenly inverted from defense to offense and vice versa.

\section{How affordances interact}

The moral of the foregoing analysis is quite general: subtle "invitations" to make the opponent attack in a desirable way, induced perceptual error while attacking, physically manipulating the opponent's nascent affordances, and affordance surfing to maximize energyoptimal paths showcase how interpersonal dynamics lead to a real-time interplay of individual affordances.

\section{Toward a triadic ontology}

How is it, then, that affordances interact? To recap the argument, as soon as agents constrain one another kinetically (i.e., through physical coupling) or through vision (i.e., through informational coupling), the status of their own affordances is subject to influence by another person. Based on this, we may define interacting affordances in a threefold way: (a) their condition of possibility is a sensorimotor resonance loop that continuously couples agents, (b) this enables agents to modulate one another's affordances through prior or concurrent actions or even modulate their entire field of action, (c) which results in emergent dynamics.

Which specific affordances arise (and when) thus depends on properties of the engagement itself and possibly unique trade-offs as the interaction loops back upon itself. The central importance of the engagement makes commonplace generalizations to the effect that situation $\mathrm{X}$ offers affordance $\mathrm{A}_{\mathrm{X}}$ risky. The interplay of the strategic modes of engagement of two agents-depending on expertise, preferences, and strategies of both-can either block or highlight $\mathrm{A}_{\mathrm{X}}$. To make matters yet more complex, modes of engagement can be switched during interaction, such that a new set of affordances appears.

Generally, affordance theory is well advised to consider the implications from studies of auto and cross-catalyzing interaction dynamics (Dale, Fusaroli, Duran, \& Richardson, 2014; Fogel, 2006, 2011; Fusaroli et al., 2015; Marsh, Johnston, Richardson, \& Schmidt, 2009; Oullier \& Kelso, 2009; Tschacher, Schiepek, \& Brunner, 1992). In systems with a mix of excitatory and inhibitory feedback loops between multiple elements, macro-patterns can stabilize temporarily and begin to exercise downward causation on the elements. ${ }^{9}$ This selforganization can make the interactive dynamic an ontological player in its own right. Affordance theory should thus begin to explain how the emergent interpersonal dynamic constrains and enables agents. In settings such as Aikido where affordances emerge interactively, the dualistic agent-agent relation needs to be replaced by a triadic agent-agent-

\footnotetext{
${ }^{9}$ On the asset side, cross-catalysis — sometimes called "enslaving" through the macro-dynamic — can boost agents' ability to jointly solve a problem or act as a team (Auvray, Lenay, \& Stewart, 2009; Riley, Richardson, Shockley, \& Ramenzoni, 2011). The flip side of the coin is that self-organization can generate seeming paradoxes. A familiar sensorimotor example is starting a dynamic of mirror movements with another pedestrian, although both want to pass by quickly. Or think of situations when we seem incapable of discontinuing a row although all involved parties hate it, or of dysfunctional mutual role assignments in families (Granic, Dishion, \& Hollenstein, 2003). Even political conflict escalation (Vallacher, Coleman, Nowak, \& Bui-Wrzosinska, 2010) and sociohistorical phenomena like fascism can be an expression of self-amplifying effects between collective emotions; crystallizing concepts; and social psychological mechanisms like contagion, group alignment, or constructed stereotypes of others (Ciompi \& Endert, 2011). Agents are locked in dynamics hard to escape individually.
} 
dynamics relation. In other words, it is insufficient to define affordances exclusively relative to individual agencies or a linear relationship between these. They must, among other things, be defined relative to emergent collective patterns, which are the outcome-if we wish-of the dynamically self-organizing relation of multiple agent-environment relations. Collective dynamics may then comprise an irreducible ontological entity, although to which degree remains an open empirical question. ${ }^{10}$

\section{Beyond methodological individualism}

All this notwithstanding, we emphasize that modelling collective dynamics exclusively at the level of the dyadic macro-system is not a real option for affordance theory, for two reasons. First, although individual intentions and actions cannot be the sole loci of explanation, as the emergent dynamic possesses a degree of its own autonomy, agents always retain some individual autonomy (De Jaegher, Di Paolo, \& Gallagher, 2010). Second, affordances by definition pertain to agents and not to dyadic collectives, although they inform these collectives via actions. Any modelling of affordance landscapes must remain agent relative, even when their causation is interactive. A qualitative methodology like ours traces the individual micro-contributions and their perspectival affordances within a collective dynamic. The stream of affordances is best described individually for both agents and then connected. In analyzing different interaction scenarios we have tried to reconstruct at which specific point person A perceives an affordance, acts on it, and how this creates further affordances for person $\mathrm{B}$ - a cascading process of cross-cueing from which a unique collective dynamic arises.

\section{Antagonistic interaction and beyond}

When two agents are locked in combat and strategically try to thwart and nullify, preempt, curb, or recontextualize each other's efforts, this arguably creates collective dynamics of a peculiar sort. One peculiarity is that definite symmetry breaking is the success condition, which differs in principle from continued playfulness one might see in social dancing or jazz. A second peculiarity is that-precisely because it pays off for the opponent to remain aware of one's affordances-the best martial arts policy is to either conceal information about one's intentions or be so quick that the opponent finds no time to respond. One actually wants to encourage a late or vague onset of affordance perception. Concealing information contrasts with all sorts of cooperative interaction, where skilled agents maximize information access to each other (see below). Third, where agents begin to vie a precarious and potentially fluctuating kind of emergence occurs, which is only kept at bay through the refined control skills of the victorious agent who reduces the opponent's degrees of freedom effectively and through basic safety constraints both agents adhere to. Operating in a precarious zone, with affordances near the subjective usability threshold may be quite natural for all sorts of adversarial interaction. Hence, brinkmanship is needed.

The fact of operating in this state of criticality is why just good-enough affordances dominate in many martial arts situations and can suddenly degenerate or flip into something completely different. Criticality is also the precondition of what we termed affordance

\footnotetext{
${ }^{10}$ Not all collective dynamics display strong emergence. Van Orden, Holden, and Turvey (2003) defined a certain class of systems as establishing interaction-dominant dynamics that begin to "enslave" the intrinsic dynamics of the components.
} 
surfing. When one affordance degenerates another better one opens, given sufficient enabling skills or simply the ability to spot and exploit it. That said, criticality is not unique to antagonism. In other studies our team found that in the collaborative dance skill of Contact Improvisation (Kimmel, Hristova, \& Kussmaul, 2018; Torrents, Castañer, Dinušová, \& Anguera, 2010) unplanned emergence is highly frequent and equally approaches criticality. When it does, affordance surfing is considered one of the central joys of the dance. However, it is handled differently than Aikido because even surprises involve negotiation and are made agreeable for the partner. Even highly emergent states remain controllable for everyone. Dancers actively procure the agreement of their partners to almost anything they do and rarely, if ever, use brute force. Although both agents bring their creative impulses to the interaction by augmenting, tweaking or transforming what the partner is concurrently doing, they take care that mutually beneficial and safe synergies arise. What is more, agents reciprocally compensate for one another's glitches (Riley et al., 2011), and responsibly assist their partners in certain techniques such as lifts. For all these reasons dynamic instabilities remain manageable even when they are sought for purposes of creativity. In sum, what makes Contact Improvisation different from Aikido (besides the relatively unconstrained form and the openness of goals) is that interaction is cooperative and thus criticality is managed by jointly seeking a new pattern that suits both dancers.

In cooperative interaction systems that operate under asymmetric decision conditions the overall power of dyadic self-organization is smaller (see Footnote 10). For example, in Tango argentino (Kimmel, 2012; 2018) followers are merely in charge of proper execution of their part of a move, whereas leaders decide for both. Choosing movements is not the followers' job. Followers restrict themselves to complementing what the leaders have invited; independent follower actions - flourishes mostly - never impact the leader, and when a follower occasionally micro-compensates for a leader's technical glitch, this remains subtle too. Compared with Contact Improvisation even Tango leaders themselves don't get nearly as many impulses from their partners to comodulate because followers give a measured response that comes later in time. (In Contact Improvisation both dancers may start something simultaneously, resulting in interesting situations that need to be coped with.) The only incisive comodulations that do happen in Tango occur when a leader invites a follower's step or leg swing and once the energy is freed, decides to "convert" it to something else to the follower's surprise. In any case, relatively moderate emergence results compared with Contact Improvisation dancing or Aikido, where both agents have the power to decide what happens and this mixes in unexpected ways.

\section{Conclusion}

Our "inside view" of the martial art Aikido illustrates nicely just how complex an ethnographic take on affordances in a sophisticated skill domain can (and perhaps should) be. We set out to show how affordances become sensitive to context, skill, strategy, and cross-catalytic effects among interaction dynamic parameters. This also gave us a platform for adding specifying concepts to the received theory of affordances, for providing some taxonomy, and for rethinking the ontology of affordances in nonscripted interactions.

Expanding on Gaver, Heft, Hodges, Bruineberg, Van Dijk, and Rietveld we depicted affordances as intention bound and contextual as well as subject to community-based constraints like safe practice and an ethos of respect and learning. Our ethnographic approach employed 
affordances as a functional semantics of interaction and skill. We mostly framed this from the defender's perspective: In an Aikido bout the required leverage for breaking the interaction symmetry comes from a mix of sensorimotor skills: readiness, early perception, movements too quick to react to or preparations concealed long enough, actions so precise they leave no (painless) degrees of freedom open, and the ability to extend into the opponent's body and bring the joint macro-system under one's own control. Our approach to skills has nested levels. It analyzes micro-skills, embedded within causally cumulating perceptionaction streams, which are in turn embedded in enduring habits: Thus, posture, alignment, gaze, breath, tone, and attention may be said to prepare for all sorts of proper Aikido movements. These high-timescale "presettings" supply what we dubbed proto-affordances, which, by activating internal structural (thus frequently somewhat hidden) synergistic elements, ensure general action-readiness for engaging competently with an opponent. One temporal level down, we see short-lived technical skills such as stepping out of the line of attack or initiating a lever. It turns out that a wide range of micro-strategies may be deployed at this timescale to create and improve affordances, regain lost ones, or simply keep the dynamic in a zone where a sizeable affordance field remains in reach. Interaction competency here requires a set of micro-skills for active perception of (prospective) affordances, for scaling up affordances that "beckon" in the distance, for preserving affordances when the opponent tries to thwart you, and indirectly enabling preparations that reach over phase-boundaries. Two perhaps rather Aikido specific micro-skills that shape the opponent's perception were induced perceptual error and induced action delays through "hazing."

Aikido is fundamentally about handling an opponent's aggression through finely adjusted coregulation, not through unfurling a script. It is grounded in the belief that blending with aggressive energy confers defensive advantage and the ability to control an opponent without harming him or her. Hence, one goes with the attacker's energy, never against it. So too the spacing, force, and timing of a given technique always respond to dynamically arising contingencies, and in freestyle practice even the kind of preferred technique may only be chosen as the interaction unfolds. Consequently, an acute sensitivity for open energy paths is one of the hallmarks of affordance expertise in Aikido. Depending on the interaction, these affordances may suggest continuing the present task, and perhaps modulating it; or the affordances call for task reparametrization, notably when an opponent blocks a technique. There is a special skill to feeling and, when needed, to switching to a better affordance on-the-fly to preserve energy optimality.

The hierarchical interaction structure of Aikido holds a general lesson for future affordance research. Defeating an attacker can only happen over successive phases (evasion, contact, lever/throw execution, guiding the opponent down, fixation). This implies that a defender must serially enable micro-affordances by completing one phase and beginning the next. To capture how affordances manifest themselves across different timescales, a central terminological distinction was drawn between decision-related main affordances appearing at transitional junctures and merely execution-related micro-affordances in between. The former category supports the real-time selection of the trajectory and the preferred defensive technique in freestyle Aikido practice. The latter category specifies transient affordances required for motor control and, because the action elements in the Aikido repertoire are diverse, these affordances have quite diverse specifying information. As a further distinction we added that a global level of affordance monitoring arises above these two categories: as soon as physical contact is made, Aikido practitioners monitor how upright their axis is (or 
how bent the opponent's) as well as perceived energy efficiency in the interplay of force while grappling.

Finally, efforts were directed at giving affordances a genuine interactivity-based framing. We began by noting that the opponent's perceptual finesse, technical skill, and strategy codetermine which affordances an Aikido practitioner perceives. An affordance's informational clarity and attractiveness to you depends as much on your opponent as on yourself. More important still, the dynamic of interactive engagement itself deserves a privileged explanatory role. Here we emphasized that (a) both agents' perspectival affordance field causally emerges from the reciprocal engagement, (b) affordances are dynamically correlated but (c) may flip nonlinearly, and (d) self-organizing interpersonal dynamics emerge from a multiparametric field of strategically relevant factors.

The general upshot for ontology and our takeaway message is that interactivity-based affordances are not fully definable relative to an agent or even to a summation of both agents but only relative to their dynamic entanglement, that is, the history of cross-causation and the self-organizing properties of their unique engagement. We thus posit an emergent interactive field in which individual affordances dynamically correspond to one another and, furthermore, reciprocally generate each other-hence our notion of "interacting affordances." In effect, any affordance's "perceivability" or "doability" is not exclusively body scaled or skill scaled or, in fact, agent sided as such. It is equally scaled relative to emergence. It is in this sense that ecological theory should rethink the received ontology of affordances in a genuinely emergentist spirit for the noncooperative activity we see in martial arts and, mutatis mutandis, other kinds of dynamic engagements between agents.

\section{Acknowledgments}

We thank David Nestelberger for helping with the analysis; Dayana Hristova for helping with the data collection; and Richard Schmidt, Jelle Bruinberg, and two anonymous reviewers for suggested improvements. We also thank 6 anonymous Aikido practitioners for their generous participation in interviews and 13 practitioners for participating in think-alouds. We are grateful to Priscilla Hill for proofreading.

\section{Funding}

This research was funded by the Austrian Science Fund (FWF) through Project P-23067.

\section{References}

Araújo, D., Davids, K., \& Hristovski, R. (2006). The ecological dynamics of decision making in sport. Psychology of Sport and Exercise, 7(6), 653-676. doi:10.1016/j.psychsport.2006.07.002

Auvray, M., Lenay, C., \& Stewart, J. (2009). Perceptual interactions in a minimalist virtual environment. New Ideas in Psychology, 27(1), 32-47. doi:10.1016/j.newideapsych.2007.12.002

Ballard, D. H., Hayhoe, M. M., Pook, P. K., \& Rao, R. P. N. (1997). Deictic codes for the embodiment of cognition. Behavioral and Brain Sciences, 20(4), 723-767. doi:10.1017/S0140525X97001611

Bernstein, N. A. (1967). The coordination and regulation of movements. London, UK: Pergamon.

Bernstein, N. A. (1996). On dexterity and development. In M. L. Latash \& M. T. Turvey (Eds.), Dexterity and its development (pp. 1-244). Mahwah, NJ: Erlbaum. 
Bourbousson, J., Sève, C., \& McGarry, T. (2010a). Space-time coordination dynamics in basketball: Part 1. Intra- and inter-couplings among player dyads. Journal of Sports Sciences, 28(3), 339-347. doi:10.1080/02640410903503632

Bourbousson, J., Sève, C., \& McGarry, T. (2010b). Space-time coordination dynamics in basketball: Part 2. The interaction between the two teams. Journal of Sports Sciences, 28(3), 349-358. doi:10.1080/02640410903503640

Bruineberg, J., \& Rietveld, E. (2014). Self-organization, free energy minimization, and optimal grip on a field of affordances. Frontiers in Human Neuroscience, 8, 599. doi:10.3389/fnhum.2014.00599

Caron, R. R., Coey, C. A., Dhaim, A. N., \& Schmidt, R. C. (2017). Investigating the social behavioral dynamics and differentiation of skill in a martial arts technique. Human Movement Science, 54, 253-266. doi:10.1016/j.humov.2017.05.005

Chemero, A. (2009). Radical embodied cognitive science. Cambridge, MA: MIT Press.

Ciompi, L., \& Endert, E. (2011). Gefühle machen Geschichte [Feelings make history]. Göttingen, Germany: Vandenhoek \& Ruprecht.

Costall, A. (2012). Canonical affordances in context. AVANT: Pismo Awangardy Filozoficzno-Naukowej, 2, 85-93.

Creem-Regehr, S. H., Gagnon, K. T., Geuss, M. N., \& Stefanucci, J. K. (2013). Relating spatial perspective taking to the perception of other's affordances: Providing a foundation for predicting the future behavior of others. Frontiers in Human Neuroscience, 7, 596. doi:10.3389/fnhum.2013.00596

Czarnitzki, D., Hottenrott, H., \& Thorwarth, S. (2011). Industrial research versus development investment: the implications of financial constraints. Cambridge Journal of Economics, 35(3), 527-544. doi:10.2139/ssrn.1494312

Dale, R., Fusaroli, R., Duran, N. D., \& Richardson, D. C. (2014). The self-organization of human interaction. In B. H. Ross (Ed.), Psychology of learning and motivation (Vol. 59, pp. 43-95). Cambridge, MA: Academic Press.

Davids, K., Hristovski, R., Araújo, D., Balagué, N., Button, C., \& Passos, P. (Eds.). (2014). Complex systems in sports. Milton Park: Routledge, UK.

Davis, T. J. (2009). Perceiving affordances for joint action (Master's thesis, University of Cincinnati).

Davis, T. J., Riley, M. A., Shockley, K., \& Cummins-Sebree, S. (2010). Perceiving affordances for joint actions. Perception, 39(12), 1624-1644. doi:10.1068/p6712

De Jaegher, H., Di Paolo, E., \& Gallagher, S. (2010). Can social interaction constitute social cognition? Trends in Cognitive Sciences, 14(10), 441-447. doi:10.1016/j.tics.2010.06.009

Degenaar, J., \& O'Regan, J. K. (2017). Sensorimotor theory and enactivism. Topoi, 36(3), 393-407. doi:10.1007/s11245-015-9338-z

Di Paolo, E., \& De Jaegher, H. (2007). Participatory sense-making: An enactive approach to social cognition. Phenomenology and the Cognitive Sciences, 6(4), 485-507. doi:10.1007/s11097-007-9076-9

Dreyfus, H. L. (2007). Why Heideggerian AI failed and how fixing it would require making it more Heideggerian. Artificial Intelligence, 171(18), 1137-1160. doi:10.1016/j.artint.2007.10.012

Dumas, G., Kelso, J. A. S., \& Nadel, J. (2014). Tackling the social cognition paradox through multiscale approaches. Frontiers in Psychology, 5, 882 doi:10.3389/fpsyg.2014.00882

Eiler, B. A., Kallen, R. W., Harrison, S. J., \& Richardson, M. J. (2013). Origins of order in joint activity and social behavior. Ecological Psychology, 25(3), 316-326. doi:10.1080/10407413.2013.810107

Esteves, P. T., de Oliveira, R. F., \& Araújo, D. (2011). Posture-related affordances guide attacks in basketball. Psychology of Sport and Exercise, 12(6), 639-644. doi:10.1016/j.psychsport.2011.06.007

Fajen, B. R., Riley, M. A., \& Turvey, M. T. (2009). Information, affordances, and the control of action in sport. International Journal of Sport Psychology, 40(1), 79-107.

Fogel, A. (1993). Developing through relationships: Origins of communication, self, and culture. Chicago, IL: The University of Chicago Press.

Fogel, A. (2006). Dynamic systems research on interindividual communication: The transformation of meaning-making. Journal of Developmental Processes, 1(1), 7-30.

Fogel, A. (2011). Theoretical and applied dynamic systems research in developmental science: Dynamic systems research. Child Development Perspectives, 5(4), 267-272. doi:10.1111/j.17508606.2011.00174.x 
Froese, T., \& Fuchs, T. (2012). The extended body: A case study in the neurophenomenology of social interaction. Phenomenology and the Cognitive Sciences, 11(2), 205-235. doi:10.1007/s11097-0129254-2

Fusaroli, R., Perlman, M., Mislove, A., Paxton, A., Matlock, T., \& Dale, R. (2015). Timescales of massive human entrainment. PLOS ONE, 10(4), e0122742. doi:10.1371/journal.pone.0122742

Fusaroli, R., Rączaszek-Leonardi, J., \& Tylén, K. (2014). Dialog as interpersonal synergy. New Ideas in Psychology, 32, 147-157. doi:10.1016/j.newideapsych.2013.03.005

Gallotti, M., \& Frith, C. D. (2013). Social cognition in the we-mode. Trends in Cognitive Sciences, 17 (4), 160-165. doi:10.1016/j.tics.2013.02.002

Gaver, W. (1991). Technology affordances. In S. P. Robertson, G. M. Olson, \& J. S. Olson (Eds.), CHI '91 Proceedings of the SIGCHI Conference on Human Factors in Computing Systems (pp. 79-84). New York: ACM.

Gibson, J. J. (1986). The ecological approach to visual perception. Hillsdale, NJ: Erlbaum. (Original work published 1979)

Granic, I., Dishion, T. J., \& Hollenstein, T. (2003). The family ecology of adolescence: A dynamic systems perspective on normative development. In G. R. Adams \& M. Berzonsky (Eds.), Blackwell Handbook of Adolescence (pp. 60-91).

Gray, W. (2004). Soft constraints in interactive behavior: The case of ignoring perfect knowledge inthe-world for imperfect knowledge in-the-head. Cognitive Science, 28(3), 359-382.

Harrison, S. J., \& Stergiou, N. (2015). Complex adaptive behavior and dexterous action. Nonlinear Dynamics, Psychology, and Life Sciences, 19(4), 345-394.

Heft, H. (2001). Ecological psychology in context: James Gibson, Roger Barker, and the legacy of William James's radical empiricism. Mahwah, NJ: Erlbaum.

Heft, H. (2007). The social constitution of perceiver-environment reciprocity. Ecological Psychology, 19 (2), 85-105.

Hodges, B. H. (2009). Ecological pragmatics: Values, dialogical arrays, complexity, and caring. Pragmatics \& Cognition, 17(3), 628-652. doi:10.1075/pc.17.3.08hod

Hommel, B., \& Nattkemper, D. (2011). Handlungspsychologie. Planung und Kontrolle intentionalen Handelns [Psychology of action. Planning and control of intentional action]. Berlin, Germany: Springer.

Horton, T. E., Chakraborty, A., \& St. Amant, R. (2012). Affordances for robots: A brief survey. AVANT: Pismo Awangardy Filozoficzno-Naukowej, 2, 70-84.

Hristovski, R., Davids, K., \& Araújo, D. (2006). Affordance-controlled bifurcations of action patterns in martial arts. Nonlinear Dynamics, Psychology, and Life Sciences, 10(4), 409-444.

Hristovski, R., Davids, K., \& Araújo, D. (2009). Information for regulating action in sport: Metastability and emergence of tactical solutions under ecological constraints. In D. Araújo, H. Ripoll, \& M. Raab (Eds.), Perspectives on cognition and action in sport (pp. 43-57). New York, NY: Nova Science.

Hristovski, R., Davids, K., Araujo, D., \& Passos, P. (2011). Constraints-induced emergence of functional novelty in complex neurobiological systems: A basis for creativity in sport. Nonlinear Dynamics, Psychology, and Life Sciences, 15(2), 175-206.

Ibáñez-Gijón, J., Díaz, A., Lobo, L., \& Jacobs, D. M. (2013). On the ecological approach to information and control for roboticists. International Journal of Advanced Robotic Systems, 10, 265. doi: $10.5772 / 55671$

Ingold, T. (2000). The perception of the environment: Essays on livelihood, dwelling and skill. London, UK, and New York, NY: Routledge.

Kelso, S. (1995). Dynamic patterns: The self-organization of brain and behavior. Cambridge, MA: MIT Press.

Kimmel, M. (2012). Intersubjectivity at close quarters: Shared, distributed, and superindividual imagery in tango argentino. Cognitive Semiotics, 4(1), 76-124.

Kimmel, M. (2016). Embodied "micro-skills" in tango improvisation: How a collaborative behavioral arc comes about. In F. Engel \& S. Marienberg (Eds.), Out for a walk. Das Entgegenkommende Denken [Conceptualizing that which comes your way] (pp. 57-74). Berlin, Germany: DeGruyter. 
Kimmel, M. (2017). The complexity of skillscapes: Skill sets, synergies, and meta-regulation in joint embodied improvisation. In J. Gore \& P. Ward (Eds.), Proceedings of the 13th International Conference on Naturalistic Decision Making, 20-23 June 2017 (pp. 102-109). University of Bath, UK.

Kimmel, M. (2018). A cognitive theory of joint improvisation: The case of tango argentino. In V. Midgelow (Ed.), Handbook of dance improvisation. Oxford, UK: Oxford University Press.

Kimmel, M., Hristova, D., \& Kussmaul, K. (2018). Sources of embodied creativity: Interactivity and ideation in Contact Improvisation dancing. , Behavioral Sciences, S. Koch, T. Fuchs, L. Martin, \& W. Tschacher (Eds.).

Kimmel, M., \& Preuschl, E. (2015). Dynamic coordination patterns in tango argentino: A cross-fertilization of subjective explication methods and motion capture. In J.-P. Lachaud \& N. Abe (Eds.), Dance notations and robot motion (pp. 209-236). Berlin, Germany: Springer.

Kimmel, M., \& Rogler, C. (2018). The anatomy of antagonistic coregulation: Emergent coordination, path dependency, and the interplay of parameters in Aikido. To appear in Human Movement Science.

Kirsh, D., \& Maglio, P. (1994). On distinguishing epistemic from pragmatic action. Cognitive Science, 18, 513-549. doi:10.1207/s15516709cog1804_1

Klein, G. (1998). Sources of power: How people make decisions. Cambridge, MA: MIT Press.

Mark, L. S. (2007). Perceiving the actions of other people. Ecological Psychology, 19(2), 107-136.

Marsh, K. L. (2015). Social ecological context of conversing. Ecological Psychology, 27(4), 310-334. doi:10.1080/10407413.2015.1086229

Marsh, K. L., Johnston, L., Richardson, M. J., \& Schmidt, R. C. (2009). Toward a radically embodied, embedded social psychology. European Journal of Social Psychology, 39(7), 1217-1225. doi:10.1002/ejsp.666

Marsh, K., \& Meagher, B. (2016). Affordances and interpersonal coordination. In P. Passos, K. Davids, \& J. Y. Chow (Eds.), Interpersonal coordination and performance in social systems (pp. 245-258). London, UK, and New York, NY: Routledge.

McArthur, L. Z., \& Baron, R. M. (1983). Toward an ecological theory of social perception. Psychological Review, 90(3), 215-238. doi:10.1037/0033-295X.90.3.215

McGann, M., \& De Jaegher, H. (2009). Self-other contingencies: Enacting social perception. Phenomenology and the Cognitive Sciences, 8(4), 417-437. doi:10.1007/s11097-009-9141-7

Nomikou, I., \& Rohlfing, K. J. (2011). Language does something: Body action and language in maternal input to three-month-olds. IEEE Transactions on Autonomous Mental Development, 3(2), 113128. doi:10.1109/TAMD.2011.2140113

Oullier, O., \& Kelso, S. J. A. (2009). Social coordination from the perspective of coordination dynamics. R. A. Meyers: Encyclopedia of Complexity and Systems Sciences, 8198-8212. doi:10.1007/978-0387-30440-3_486

Passos, P., Cordovil, R., Fernandes, O., \& Barreiros, J. (2012). Perceiving affordances in rugby union. Journal of Sports Sciences, 30(11), 1175-1182. doi:10.1080/02640414.2012.695082

Passos, P., Davids, K., \& Chow, J. Y. (Eds.). (2016). Interpersonal coordination and performance in social systems. London and New York, NY: Routledge.

Petitmengin, C. (2006). Describing one's subjective experience in the second person: An interview method for the science of consciousness. Phenomenology and the Cognitive Sciences, 5, 229-269. doi:10.1007/s11097-006-9022-2

Pezzulo, G., Barca, L., Bocconi, A. L., \& Borghi, A. M. (2010). When affordances climb into your mind: Advantages of motor simulation in a memory task performed by novice and expert rock climbers. Brain and Cognition, 73(1), 68-73. doi:10.1016/j.bandc.2010.03.002

Pinder, R. A., Davids, K., \& Renshaw, I. (2012). Metastability and emergent performance of dynamic interceptive actions. Journal of Science and Medicine in Sport, 15(5), 437-443. doi:10.1016/j. jsams.2012.01.002

Reed, E. (1996). Encountering the world: Toward an ecological psychology. New York, NY: Oxford University Press.

Richardson, D. C., Washburn, A., Harrison, S. J., \& Kallen, R. W. (2016). Symmetry and the dynamics of interpersonal coordination. In P. Passos, K. Davids, \& J. Y. Chow (Eds.), Interpersonal coordination and performance in social systems (pp. 65-81). New York, NY: Routledge. 
Richardson, M. J., Marsh, K., \& Baron, R. M. (2007). Judging and actualizing intrapersonal and interpersonal affordances. Journal of Experimental Psychology: Human Perception and Performance, 35 (4), 845-859. doi:10.1037/0096-1523.33.4.845

Rietveld, E., \& Kiverstein, J. (2014). A rich landscape of affordances. Ecological Psychology, 26(4), 325352. doi:10.1080/10407413.2014.958035

Riley, M. A., Richardson, M. J., Shockley, K., \& Ramenzoni, V. C. (2011). Interpersonal synergies. Frontiers in Psychology, 2, 38. doi:10.3389/fpsyg.2011.00038

Saltzman, E., \& Caplan, D. (2015). A graph-dynamic perspective on coordinative structures, the role of affordance-effectivity relations in action selection, and the self-organization of complex activities. Ecological Psychology, 27(4), 300-309. doi:10.1080/10407413.2015.1086228

Saltzman, E. L., \& Munhall, K. G. (1992). Skill acquisition and development: The roles of state-, parameter-, and graph-dynamics. Journal of Motor Behavior, 24(1), 49-57. doi:10.1080/ 00222895.1992.9941600

Saltzman, E., Nam, H., Goldstein, L., \& Byrd, D. (2006). The distinction between state, parameter and graph dynamics in sensorimotor control and coordination. In L. Latash Mark \& F. Lestienne (Eds.), Motor control and learning (pp. 63-73). New York, NY: Springer.

Schmidt, R. C. (2007). Scaffolds for social meaning. Ecological Psychology, 19(2), 137-151.

Silva, P., Garganta, J., Araújo, D., Davids, K., \& Aguiar, P. (2013). Shared knowledge or shared affordances? Insights from an ecological dynamics approach to team coordination in sports. Sports Medicine, 43(9), 765-772. doi:10.1007/s40279-013-0070-9

Steffensen, S. V. (2013). Human interactivity: Problem-solving, solution-probing and verbal patterns in the wild. In S. J. Cowley \& F. Vallée-Tourangeau (Eds.), Cognition beyond the brain (pp. 195221). London, UK: Springer London.

Sutton, J. (2007). Batting, habit and memory: The embodied mind and the nature of skill. Sport in Society, 10(5), 763-786. doi:10.1080/17430430701442462

Sutton, J., McIlwain, D., Christensen, W., \& Geeves, A. (2011). Applying intelligence to the reflexes: Embodied skills and habits between Dreyfus and Descartes. Journal of the British Society for Phenomenology, 42(1), 78-103. doi:10.1080/00071773.2011.11006732

Torrance, S., \& Froese, T. (2011). An inter-enactive approach to agency: Participatory sense-making, dynamics, and sociality: Humana.Mente, 15, 21-53.

Torrents, C., Castañer, M., Dinušová, M., \& Anguera, M. T. (2010). Discovering new ways of moving: Observational analysis of motor creativity while dancing Contact Improvisation and the influence of the partner. The Journal of Creative Behavior, 44(1), 53-69. doi:10.1002/j.2162-6057.2010. tb01325.x

Torrents, C., Hristovski, R., Coterón, J., \& Ric, A. (2016). Interpersonal coordination in Contact Improvisation dance. In P. Passos, K. Davids, \& J. Y. Chow (Eds.), Interpersonal coordination and performance in social systems (pp. 94-108). Abingdon, UK: Routledge.

Torrents Martín, C., Ric, Á., \& Hristovski, R. (2015). Creativity and emergence of specific dance movements using instructional constraints. Psychology of Aesthetics, Creativity, and the Arts, 9(1), 65-74. doi:10.1037/a0038706

Travassos, B., Araújo, D., Davids, K., Vilar, L., Esteves, P., \& Vanda, C. (2012). Informational constraints shape emergent functional behaviours during performance of interceptive actions in team sports. Psychology of Sport and Exercise, 13(2), 216-223. doi:10.1016/j.psychsport. 2011.11.009

Tschacher, W., Schiepek, G., \& Brunner, E. J. (Eds.). (1992). Self-organization and clinical psychology (Vol. 58). Berlin and Heidelberg, Germany: Springer.

Turvey, M. T. (1992). Affordances and prospective control: An outline of the ontology. Ecological Psychology, 4(3), 173-187. doi:10.1207/s15326969eco0403_3

Turvey, M. T., \& Carello, C. (2011). Obtaining information by dynamic (effortful) touching. Philosophical Transactions of the Royal Society B: Biological Sciences, 366(1581), 3123-3132. doi:10.1098/rstb.2011.0159

Vallacher, R. R., Coleman, P. T., Nowak, A., \& Bui-Wrzosinska, L. (2010). Rethinking intractable conflict: The perspective of dynamical systems. American Psychologist, 65(4), 262-278. doi:10.1037/ a0019290 
van Dijk, L., \& Rietveld, E. (2017). Foregrounding sociomaterial practice in our understanding of affordances: The skilled intentionality framework. Frontiers in Psychology, 7, 1969. doi:10.3389/ fpsyg.2016.01969

Van Orden, G. C., Holden, J. G., \& Turvey, M. T. (2003). Self-organization of cognitive performance. Journal of Experimental Psychology: General, 132(3), 331-350. doi:10.1037/0096-3445.132.3.331

Warren, W. H. (1984). Perceiving affordances: Visual guidance of stair climbing. Journal of Experimental Psychology: Human Perception and Performance, 10(5), 683-703.

Warren, W. H. (2006). The dynamics of perception and action. Psychological Review, 113(2), 358-389. doi:10.1037/0033-295X.113.2.358

Westbrook, A., \& Ratti, O. (2001). Aikido and the Dynamic Sphere: An Illustrated Introduction. North Clarendon, VT: Charles E. Tuttle Publishing Co.

Wolpert, D. M., Doya, K., \& Kawato, M. (2003). A unifying computational framework for motor control and social interaction. Philosophical Transactions of the Royal Society London, 358, 593-602. doi:10.1098/rstb.2002.1238

Yamamoto, Y., Okumura, M., Yokoyama, K., \& Kijima, A. (2016). Interpersonal coordination in competitive sports contests: Martial arts. In P. Passos, K. Davids, \& J. Y. Chow (Eds.), Interpersonal coordination and performance in social systems (pp. 179-184). London, UK, and New York, NY: Routledge.

Zukow-Goldring, P. (2006). Assisted imitation: Affordances, effectivities, and the mirror system in early language development. In M. A. Arbib (Ed.), Action to language via the mirror neuron system (pp. 469-500). Cambridge, MA: Cambridge University Press. doi:10.1017/CBO9780511541599.015 